\title{
NO RASTRO DO "SUBTERRÂNEO CELESTE". OITO TESES SOBRE A TRANSFORMAÇÃO DA RELIGIÃO, DE ERNST BLOCH $^{12}$
}

\author{
Beat Dietschy ${ }^{3}$
}

\begin{abstract}
Resumo:
O objetivo das teses é delinear as principais características da metarreligião de Bloch. Ela é compreendida como sendo uma herança da tradição religiosa, a qual emerge de uma apropriação e transformação crítica do simbolismo religioso. Seu princípio hermenêutico pode ser caracterizado como sendo um princípio emancipatório e subversivo, porque libera o acesso a fontes desperdiçadas e reprimidas da história dos oprimidos. A crítica à religião a isso associada volta-se contra uma deformação, conformada com a dominação, daquilo que foi transmitido pela religião e contra uma transferência para o além e a hipostasia ahistórica das esperanças religiosas. Transcendência se transforma em transcender historicamente imanente. Ela, no entanto, se diferencia de uma secularização rasa do religioso, pelo fato de que objetiva a realização dos conteúdos utópicos e dos sonhos desejantes aí contidos. Por isso ela pode ser designada, com Walter Benjamin, de "crítica salvadora".
\end{abstract}

Palavras-chave: metarreligião, crítica à religião, transcender imanente, "crítica salvadora".

\section{AUF DER SPUR VON 'HIMLISCH UNTERIRDISCHEM’. ACHT THESEN ZUR ERNST BLOCHS TRANSFORMATION DER RELIGION}

\section{Zusammenfassung:}

Ziel der Thesen ist es, die Hauptmerkmale von Blochs Meta-Religion zu umreissen. Diese wird als ein Erbe an religiöser Tradition verstanden, das aus einer kritischen Aneignung und Verwandlung religiöser Symbolik hervorgeht. Ihr hermeneutisches Prinzip kann als ein emanzipatorisches und subversives charakterisiert werden, weil es Zugänge zu den verschütteten und verdrängten Quellen der Geschichte der Unterdrückten freilegt. Die damit verbundene Religionskritik wendet sich gegen eine herrschaftskonforme Verformung religiöser Überlieferungen und gegen eine Verjenseitigung und ahistorische Hypostasierung religiöser Hoffnungen. Transzendenz transformiert sie in geschichtsimmanentes Transzendieren. Sie

1 Título original: Aufder Spur von 'himlisch Unterirdischem'. Acht Thesen zu Ernst Blochs Transformation der Religion. Publicado originalmente em: ZEILINGER, Doris (Org.). "Der Zukunft auf der Spur". Transformation aus der Perspektive Ernst Bloch. Vorschein 35. Jahrbuch der Ernst-Bloch-Assoziation. Antogo Verlag: Nürnberg, 2018 p. 185-197. O resumo foi especialmente elaborado pelo autor para o presente texto (N.T.).

2 Rosalvo Schütz traduziu este artigo. Schütz é docente de Filosofia na Universidade Estadual do Oeste do Paraná - UNIOESTE. Bolsista de produtividade do CNPq. A tradução foi realizada durante pósdoutorado em filosofia na Universidade Católica do Rio Grande do Sul (PUCRS). E-mail: rosalvoschutz@hotmail.com.

3 Doutor em Filosofia e teólogo. Foi o último assistente de Ernst Bloch, tendo contribuído na organização de obras do próprio Bloch. Publicou vários livros e artigos sobre sua filosofia. É integrante da Associação Ernst Bloch [Ernst-Bloch-Assoziation] e membro fundador da Sociedade Internacional Ernst Bloch [Interntionalen Ernst-Bloch-Gesellschaft]. Atuou como conselheiro e jornalista em projetos de desenvolvimento intercultural na América Latina. Foi docente de Ética na Suíça. Gerenciou a organização "Pão para Todos" e atualmente é presidente da organização não governamental Comundo, em Lucerna/Suíça, além de trabalhar no jornal Neue Wege (Novos Caminhos) de Zurique e participar de projetos de pesquisa sobre globalização, teologia da libertação e filosofia intercultural. Reside em Berna/Suíça (N.T.). 
unterscheidet sich aber von einer platten Säkularisierung des Religiösen dadurch, dass sie auf Verwirklichen der darin enthaltenen utopischen Gehalte und Wunschträume abzielt. Sie kann daher mit Walter Benjamin als "rettende Kritik" bezeichnet werden.

Stichwörter: Meta-Religion, Religionskritik, immanentes Transzendieren, “rettende Kritik”.

\section{Quando Bloch pleiteia uma herança da religião, recorre a ela a fim de transformá- la em metarreligião.}

Frequentemente, quando se aborda a herança religiosa de Bloch, se dá pouca atenção a como isso pôde acontecer. Não se trata de assegurar um resto de crença, da qual ele não quisesse abrir mão. Bloch não cresceu em uma família religiosa, com a qual ele teria de ter rompido. A herança da qual fala ele a tomou para si e dela se apropriou. Aquilo que toma dos baús de tesouros (Schatzkammern) das religiões, especialmente da cristã e judaica, são preciosidades de esperança: algo messiânico, aquilo que leva ao êxodo, utopias apocalípticas e do reino. O acessar (Zugriff) e recorrer (Rückgriff) a estes tesouros ocorre desde fora, num distanciamento em relação àquelas tradições religiosas, e não vindo do interior dessas. Aquilo de que se apropria é testado, modificado e utilizado para, a partir daí, ser usado para construir algo novo. "Nada a esquecer, tudo a modificar" é o lema de Bloch, e a práxis associada a isso deve ser "dialética, esperançosa, herdável por excelência” (Bloch, 1977b, p. 157) ${ }^{4}$.

2. Bloch lida com a religião de modo subversivo. Persegue o "celestial" desde a perspectiva da "toupeira sous la terre" e o (re) localiza enquanto algo "subterrâneo celeste" ("himmlisch Unterirdisches").

Quando Bloch se refere ao campo da religião, para ele geralmente se trata de rastrear o "utópico-subversivo" (Bloch, 1977b, p. 121), o qual, por mais que tenha sido formatado desde cima pela dominação, ela continuaria contendo. Para tanto, é necessário um trabalho de transformação junto às religiões tradicionais. Ele não quer dar continuidade à religião hegemônica, mas sim trazer à luz do dia "a história subterrânea da revolução" (Bloch, 1973, p. 206), que nela está contida. O que foi e o que é transmitido ele conta de outro modo.

\footnotetext{
4 Quando disponíveis edições brasileiras, as referências são feitas em conformidade com as mesmas; quando não, são traduzidas diretamente do original alemão, mantendo-se a referência da obra original citada (N.T.).
}

\begin{tabular}{|l|l|l|l|l|}
\hline Q & Ano 10 & n. 21 & Janeiro - Abril 2021 & p. $37-52$ \\
\hline
\end{tabular}


Daí resultam "subterrâneos celestes” (Bloch, 1973, p. 206), um modo plebeu de leitura daquilo que foi transmitido, na qual o esmoleiro e o rei trocam de lugares, como naquela história hassídica que Bloch reconta nos Spuren (1977f, p. 99 ss.) sob o título de Queda no agora (Fall ins Jetzt). Perguntado pelo rabino o que ele se desejaria, o mendigo esfarrapado recém-chegado diz: "Eu gostaria de ser um grande rei e ter um grande país". E sua história cheia de fantasia utópica - "em cada cidade eu teria um palácio, e na mais bonita delas estaria a minha residência, de ônix, sândalo e mármore" - termina, depois de uma guerra perdida, com ele recusando púrpura e arminho, despindo-se até uma última camisa e fugindo, de seu país queimado, como um desconhecido, "em direção a outras pessoas, que nada sabem de mim, que nada querem de mim, estou a salvo e desde ontem à noite estou aqui sentado". 'Por que então desejou tudo isso, se perderá tudo de novo', pergunta o rabino. Porque ele já teria alguma coisa, contrapõe-lhe o mendigo, a dizer, uma camisa.

A camisa, com a qual os judeus o presenteiam enquanto riem e balançam a cabeça, apenas encobre de modo improvisado o agora estranhamente ambíguo, no qual a história termina. É um “avanço para fora do ser-aqui em meio a um sonho. Linguisticamente mediado pela transposição espertalhona, a qual o mendigo contador retira da forma de sonho, com a qual ele inicia, e que de repente, por meio do histórico, toma como presença real” (Bloch, 1977f, p. 99).

Essa história contém in nuce a filosofia de Bloch, e isso tanto no que se refere ao caminho de seu devir quanto ao arco argumentativo lançado na medida em que inverte materialisticamente aquilo que religião e utopia foram e, de modo transformado, as incorpora ao marxismo. Ela mostra como o não ter e o desejar podem seduzir para mundos dos desejos imaginários e abre, simultaneamente, um alçapão para dentro do aqui e agora. No entanto, seu contar não conduz simplesmente do celestial de volta para o existente vale de lágrimas terreno, do rei para o mendigo. E não é apenas um mendigo com camisa que emerge desse conto. Nele surge uma presença com subversão e faíscas utópicas. Na primeira versão do conto, Bloch comenta: "ainda ninguém substruiu (substruierte), como o mendigo, a dura realidade com correntes espirituosas, com idealismos livremente flutuantes para, somente a partir destes, então alcançar aquela” (Bloch, 1923a, p. 135). Esse desvio faz sentido especialmente em relação à questão de como pode ser iniciada a transformação de relações enrijecidas. Com a "substrução" que aqui é empreendida, emerge uma espécie de "infraestrutura" que - diferentemente da compreensão reduzida 
de base econômica do marxismo vulgar - abarca também o poder explosivo do fator subjetivo, o qual mina o real com imaginação esperançosa.

Não é apenas a pobreza que causa transformação. Sobre isso outra história que nos Spuren é sobrescrita como "Pão e Jogos" [Brot und Spiele] (Bloch, 1977f, 28 ss.) - nos informa. Ela trata de alguém que repentinamente empobrece - como foi a experiência do próprio Bloch na I Guerra Mundial, na emigração suíça. A miniatura da história conclui que "o impulso revolucionário nunca vem só da pobreza [...] mas da profunda demanda por cura e felicidade, a partir da posse não possuída (unbesessenen Besitz) da natureza humana, na forma como ela é preservada de modo suficientemente oculto e disfarçado entre os pobres, apesar de sua pobreza e privações de direitos" (Bloch, 1923, p. 124) $)^{5}$. Também aqui há algo subterrâneo celeste, de certo modo no porão da própria vida, conduzindo consigo sonhos que implodem o calabouço do mundo, messiânicas fantasias de libertação, como elas foram compostas por Brecht e Weill na canção da Jenny dos Piratas (Seeräuberjenny) na Ópera dos três vinténs $(\text { Dreigroschenoper })^{6}$, com a qual a Ópera dos três vinténs finaliza enquanto "paródia de ópera" [Opernparodie]. O “Oops" de Jenny "é tão apocalíptico quanto você quer", observa Bloch, e "o mensageiro do rei, com quem a Ópera fecha como uma 'paródia de ópera', é da região de Fidelio ${ }^{7}$, isso é muito palpável; mesmo que o pathos da salvação apenas transpasse como um pão de manteiga através de um papel” (Bloch, 1977e, p. 394).

\section{Bloch empreende uma des-ontologização crítica da religião.}

Se o mundo em que vivemos é "perpassado por atrocidades e esperanças, metade amontoado de farrapos, metade figura, que ainda está em formação" (Bloch, 1977e, p. 573), isso também dever ser expresso na forma de pensar. No caso de Bloch, até mesmo no caso dos textos filosóficos, em última análise se trata de um pensar narrativo, pois também nesses ele tensiona um arco que efetivamente não se fecha em círculo. Discrepâncias não são ocultadas, contradições não são submetidas a uma solução, mas minam, enquanto diferenças preservadas, o chão da realidade. Não é construída uma

5 No mesmo contexto nos Spuren consta o seguinte: "Ela não advém nunca apenas da pobreza [...] mas do sentimento de uma 'posse' não possuída, que chega até a gente” (Bloch, 1977f, p. 29).

6 Trata-se da obra de Kurt Weill e Bertold Brecht (1988) traduzida no Brasil por Wolgan Bader e Marcos Roma Santa (N.T.).

7 Referência à opera Fidélio, de Beethoven, que Bloch mais apreciava, de modo especial a cena da libertação de Fidélio da prisão (N.T.).

\begin{tabular}{|c|c|c|c|c|}
\hline Qevista Dialeatus & Ano 10 & n. 21 & Janeiro - Abril 2021 & p. $37-52$ \\
\hline
\end{tabular}


realidade verdadeira, mas a instituída é submetida à forma-desejo ou "substruída", juntamente com sua incongruência e não existência desde o obscuro do instante vivido (cf. 1977c, p. 369).

Derrida iria falar de uma 'hantologia', que precede qualquer ontologia adequadamente construída e que retorna de modo 'fantasmagórico' (Derrida, 2004, p. 10). O ponto de partida de Bloch é o "isto" ainda vazio daquilo que é algo, que está posto no escuro de cada instante. Algo que ainda não se manifestou de modo adequado, o que é reconhecido, por Bloch, na persistente frase curta de Paulo no Mahagonny ${ }^{8}$ de Brecht: "Mas algo falta"9. "Aquilo que esse isto, o possível conteúdo de sentido do seu processomundo em autoexposição experimental, o fator-isto prementemente rumo a uma manifestação adequada [...] de forma alguma já está disponível” (Bloch, 1977f, p. 31). Onde, no entanto, a existência do isto for reivindicada, é necessário objeção. Daí que, para Bloch, sem crítica da religião e da velha metafísica não ser possível pensar em salvar os conteúdos utópico-subversivos.

\section{Alvo e direção do impulso da crítica da religião de Bloch é uma mundanização (Verdiesseitigung) radical.}

Bloch empreende uma (re) localização do céu. Na autoexposição de sua filosofia, insiste que a solução para o mistério não se encontraria "acima", mas que seria antes "a proximidade, o mais próximo do imediato, que compõe o mistério" e sua solução ainda não encontrada estaria "na imanência genética e de forma alguma na transcendência hipostasiada" (Bloch, apud Pongratz, 1975, p. 03). Com Feuerbach, portanto, persegue “descelestializações" [Enthimmelungen] (Bloch, 1977, p. 281), no entanto, diferentemente desse, não pretende limitar o "retorno do celestial" ao ser humano enquanto "pensado existente" (Bloch, 1977, p. 280) ou à produção dos desejos deste. Imanência genética significa, antes, que se trata, em continuidade de pensamentos do Jovem Hegel, de "requerer [...] os tesouros, os quais foram desperdiçados no céu, enquanto propriedade dos humanos" (Bloch, 1977, p. 282). E, para validar isso não apenas na teoria, mas para se pôr de fato em posse desses tesouros, Bloch recorre aos

8 Trata-se da peça, de Bertold Brecht, Ascensão e queda da cidade de Mahagonny (Cf. Brecht, 1988).

9 Compare a contribuição de Blumentritt (2018): "Etwas fehlt" - Die Möglichkeit denken. ["Algo falta" - pensar a possiblidade].

\begin{tabular}{|c|c|c|c|c|}
\hline QRovista Dialectus & Ano 10 & n. 21 & Janeiro - Abril 2021 & p. $37-52$ \\
\hline
\end{tabular}


processos históricos, os quais permitem compreender a imanência de modo não estático, mas enquanto um "transcender" sem transcendência (Bloch, 1977, p. 15) ${ }^{10}$.

\title{
5. Trazer para o aquém e mudanização não têm o mesmo significado que secularização.
}

Hoje, muitas vezes, se fala indiferenciadamente de "secularização"11. "Secularismo", por sua vez, expressa como uma visão de mundo se emancipou de preceitos igrejeiros e se estabeleceu livre de religião. Com isso, no entanto, muitas vezes passa despercebido que o crescente afastamento de igrejas (Entkirchlichung) das sociedades ocidentais europeias não pode ser equiparado com descristianização ou com desaparecimento da religião. O progressivo desencantamento não é, como mostra a pesquisa religioso-sociológica, um caminho de mão única, mas está interligado com processos contrários de ressacralização e reencantamento, os quais trazem à tona formas não institucionalizadas de espiritualidade cristã e não cristã. A isso também pode ser atribuída a sacralização da mercadoria e do dinheiro, da cultura, da nação ou do Estado ${ }^{12}$. Como afirma Wendy Brown: “O secularismo não elimina simplesmente a religião da esfera pública, mas transforma e distribui o imaginário religioso assim como formas de consciência religiosa sobre uma sociedade por ele dominada" (2013, p. 258).

Essa disseminação do religioso Bloch descreve em um texto sobre a Rua de mão única, de Benjamin:

\begin{abstract}
Catedrais se evidenciam enquanto "estações de trem de religiões" (Religionsbahnhöfe) e, assim como essas, encontram-se também simultaneamente envoltas em olhares-alegorias: "Trens com vagões-dormitórios com destino à eternidade são, na hora da missa, expedidos daqui". Crítica às "estações de trem das religiões" sim, mas da mesma forma o trem corre em sentido contrário, ou seja, da eternidade e de seus seres mitológicos rumo à estação de trem, para aqui descarregar seus contrabandos (Bloch, 1977b, p. 370).
\end{abstract}

${ }^{10}$ Compare com Beat Dietschy (2018) - Transzendieren der Transzendenz. Ernst Blochs Versuch, Religion neu zu denken [Transcender da transcendência. A tentativa de Ernst Bloch de pensar a religião de um modo novo], p. 11-28.

${ }^{11}$ Dependendo do contexto e intenção, o conceito é utilizado muito diferenciadamente. Originalmente ele se refere à relação entre cristianismo e mundo e, nessa medida, conforme seu conteúdo, abrange retroativamente até o tempo da controvérsia das investiduras no séc. XI, com a diferenciação surgida na época entre poder celestial e poder terreno e a consequente separação entre religião e Estado (cf. Böckenförde, 1981, p. 67). Em termos da história da palavra, ela passou a ser usada com a desapropriação dos bens da Igreja no início do séc. XIX. Hoje, comumente se associa com ele a separação entre Estado e Igreja.

12 Para compreender isso, a análise do fetichismo da mercadoria e do dinheiro realizada por Marx é fundamental, pois o mecanismo básico da socialização capitalista cria "uma mistificação especificamente religiosa de poderes, objetos, coisas e relações" (Brown, 2013, p. 265).

\begin{tabular}{|l|l|l|l|l|}
\hline Govista Dialectus & Ano 10 & n. 21 & Janeiro - Abril 2021 & p. 37-52 \\
\hline
\end{tabular}


Nas ciências literárias se compreende por secularização "a transposição de um vocabulário de origem religiosa para temas e objetos mundanos" (Lange, apud Sölle, 1981, p. 90 $)^{13}$. Nesse sentido, Bloch faz uso extenso das metáforas religiosas, ocasionalmente também em conexão direta com afirmações críticas de cunho filosóficoreligioso. Assim, por exemplo, escreve em um artigo de jornal, intitulado Casa de dança e de abate [Tanz- und Schlachthaus], no qual relata uma maratona de dança em Frankfurt em 1931:

Anteriormente a gente se consolava com o céu, o qual deveria compensar os danos dessa vida. Agora, com o mesmo objetivo, aparentemente encenamos pequenas partes do inferno. Com isso, sem dúvida, alguma raiva pode ser descarregada, mas não se deixa retirar, de forma permanente, a religião do povo (Bloch, 1997, p. 132).

\section{Em vez de secularização do religioso, Bloch busca a realização do seu conteúdo utópico.}

"Secularização" também é um conceito de luta, que foi utilizado para deslegitimação da modernidade (cf. Blumenberg, 1966), mas, especialmente, do marxismo. Em seu livro publicado em 1953 e intitulado História mundial e evento de salvação (Weltgeschichte und Heilgeschehen), Karl Löwith defendeu que o ponto de vista do materialismo histórico seria uma "história da salvação na linguagem da Economia Nacional" e, fundamentalmente, não científico, uma vez que estaria "perpassado por uma crença escatológica da primeira à última frase" (Löwith, 1953, p. 48). Acima de tudo, porém, ele queria demonstrar que a filosofia da história surgia a partir da crença bíblica em uma completude [Erfüllung] e, assim, "findaria com a secularização do seu modelo escatológico" (Löwith, 1953, p. 11ss.). Isso conduziu a um debate em torno da secularização e contribuiu para que o pensamento de Bloch fosse condenado, na DDR ${ }^{14}$, como sendo uma "teoria da redenção" não marxista. Nos dias 04 e 05 de abril de 1954, numa Conferência sobre questões da filosofia blochiana, promovida pela direção do

13 Trata-se do texto de Augusto Lange Zum Problem der sprachlichen Säkularisation in der deutschen Dichtung des 18. Und 19. Jahrhundertes [Sobre o problema da secularização linguística na poesia alemã dos Séculos XVIII e XIX], citado por Sölle (1981, p. 90). No entanto, como observa Sölle, aquilo que geneticamente é chamado de secularização, do ponto de vista funcional deveria, antes, ser descrito como sacralização (Idem, p. 103).

14 República Democrática Alemã [Deutsche Demokratische Republik] (N.T.).

\begin{tabular}{|l|l|l|l|l|}
\hline Q Rovista Dialectus & Ano 10 & n. 21 & Janeiro - Abril 2021 & p. $37-52$ \\
\hline
\end{tabular}


partido da $\mathrm{SED}^{15}$, no Instituto para Filosofia da Universidade Karl Marx, de Leipzig, chegou-se, "de forma unânime à conclusão" de que essa não seria "compatível com os princípios da teoria de Marx, Engels e Lênin" (Horn, 1957, p. 48). De modo enfático, foi afirmado também que "fosse a filosofia de Bloch marxista, do marxismo 'autêntico' de nossa época, então Karl Löwith, o matador de Marx, teria razão quando tenta apresentar a teoria de Marx enquanto uma religião escatológica ou algo assim. [...] Nós, no entanto, não podemos evitar de admitir de que essa 'afirmação' de Löwith de fato se aplicaria à concepção blochiana de história" (Horn, 1957a, p. 300).

No último capítulo do Princípio Esperança, intitulado "Karl Marx e o espírito humanitário; substância da Esperança”, Bloch se posiciona detalhadamente em relação ao "negócio que gira em torno de matar Marx declarando-o antiquado" (Bloch, 2006, p. 447), de Löwith, e designa a sua tese da secularização como sendo um "tipo de denúncia de plágio"(Bloch, 2006, p. 448) que declararia Marx como mero derivado de tempos melhores e, "por assim dizer, desmascarado... como saqueador da igreja" (2006, p. 448). Bloch lembra da carta de Marx a Ruge, segundo o qual "não se trata de um grande travessão entre o passado e o futuro, mas da realização das ideias do passado" (Bloch, 2005, p. 449). "Portanto", afirma Bloch rebatendo o diagnóstico de Löwith, "um bom conteúdo de fato não se enfraquece ao ser corrigido, e é ainda mais óbvio que ele não se torna secularizado ao ser realizado depois de colocado sobre seus próprios pés" (Bloch, 2006, p. 449). Conforme indicam Francesca Vidal e Ulrich-Schöll (2017, p. 372), deve permanecer em aberto se a nomeada "Conferência de Leipzig" se refere ao manuscrito do terceiro volume do Princípio Esperança, na época já pronto para ser impresso na editora Aufbau, ou se, ao contrário, Bloch está aqui reagindo à crítica daquela. A última hipótese não me parece improvável. No entanto, chama atenção que Bloch tenha dedicado, em um lugar tão proeminente, no capítulo final de sua obra principal, sete páginas inteiras justamente a uma polêmica em torno da acusação de secularização. Também é interessante que quase ao final desse item ele escreva uma frase que, inclusive no que diz respeito à ordenação das palavras, pode ser lida muito bem enquanto uma réplica à nominada conferência do revisionismo: "Somente o marxismo criativo é o nosso tempo formulado em idéias, um tempo simultaneamente produtivo, herdador, realizador [...]" (Bloch, 2006, p. 450).

15 Trata-se do Partido Socialista Unificado da Alemanha [Sozialistische Einheitspartei Deutschlands] (N.T.).

\begin{tabular}{|c|c|c|c|c|}
\hline Qovista Dialectus & Ano 10 & n. 21 & Janeiro - Abril 2021 & p. $37-52$ \\
\hline
\end{tabular}


Impressionante permanece, em todo caso, o fato de que o conceito de secularização ocupe nessa passagem um espaço tão amplo, uma vez que em Bloch ele não tem um papel constitutivo. Quando chega a utilizá-lo, geralmente indica um "degradar" de algo que, alguma vez tendo tido um valor alto, é "liquidado" por um preço reduzido (cf. Bloch, 2006, p. 445) ${ }^{16}$. Em um colóquio em Cerisy-la-Salle em 1959, e em resposta a Kalokowski, Bloch mais uma vez afirmou enfaticamente que o marxismo não é uma escatologia: "Marx apenas afirmou: eu quero pôr a dialética hegeliana sobre seus próprios pés" (Bloch, apud Roulet, 2012, p. 347). Ele apenas enfatiza que "alguém que está sobre seus próprios pés é capaz de caminhar. Há pois, aqui, o pensamento de um movimento, o qual é totalmente desprezado na tese da secularização da escatologia" (Idem, p. 347). Bloch recorre aqui ao caminhar ereto (aufrechter Gang), o qual requer a revolução e a transformação do mundo. Sem ele não seria possível nem mesmo uma escatologia secularizada em Hegel, mas apenas uma simples mitologia e apologia do instituído (cf. Bloch, 1959).

Com isso fica claro que a "secularização" e "a força de colocar algo sobre os próprios pés" (Bloch, 2006, p. 445) de forma alguma significam a mesma coisa ${ }^{17}$. "A não ser que se compreenda secularização num sentido bem novo, marxista, que corresponda à teoria-práxis" (Bloch, 2006, p. 451). Somente assim seria, segundo Bloch, em "uma bela ironia, possível de salvar essa palavra pejorativa, de feitio tão pérfido e tornada tão traiçoeira e desvalorizada" (Bloch, 2006, p. 1615), ou seja, redimindo o programa do Jovem Marx de uma "mundanização ${ }^{18}$ [Verweltlichung] da filosofia"19. Mais tarde Marx

16 Assim ele afirma sobre o surgimento (mal e mal secular, mas adequado ao mundo) da estrutura clericalestatal do reino Carolíngio: "Floresceu uma cristandade curiosamente secularizada pela missão cultural meramente profana, incumbida unicamente de transmitir conhecimento sobre esse mundo e torná-lo suportável, sem vocação para qualquer outro" (Bloch, 1973, p. 157). No Espírito da Utopia (1977d, p. 305), ele pôde afirmar, em relação ao socialismo utópico árcade, que ele "com fundamento" é rejeitado enquanto "forma secularizada do reino milenar".

17 Raulet parece não fazer essa diferença quando põe, equivocadamente, um 'ou' em vez de um 'e' no entretítulo de Bloch "A secularização $e$ a força para colocar algo sobre os próprios pés” (Bloch, 2006, p. 445). E ainda continua: “A secularização de forma alguma conduz à simples abolição da religião [o que confere! Beat Dietschy], mas, muito mais, para a sua superação (Aufhebung) dialética por meio da realização de seu conteúdo de verdade" (2012, p. 347). Uma tal apreciação do conceito ambíguo e controverso de secularização, no meu modo de ver, não pode ser confirmado em Bloch. No contexto indicado, Bloch antes refere-se a um "negócio da secularização total" (Bloch, 2006, p. 447) e classifica seus executores de serem "epigônicos" (2006, p. 449).

18 A fim de manter a diferença entre Säkularisierung e Verweltlichung, enfatizada pelo autor, sugerimos aqui a tradução de Verweltlichung por mundanização e não por "secularização", como consta em Bloch (2006, p. 451). (N. T.)

19 Nas observações sobre sua dissertação, Marx escreve sobre uma "mundanização da filosofia" e um "tornar-se filosófico do mundo" (Marx, 1973, p. 329).

\begin{tabular}{|l|l|l|l|l|}
\hline Q Rovista 2 ialectus & Ano 10 & n. 21 & Janeiro - Abril 2021 & p. 37-52 \\
\hline
\end{tabular}


(1983, p. 21; cf. Bloch, 2006, p. 447) fala de uma 'inversão' [Umstülpen] da dialética hegeliana. Em Bloch, mundanizar, realizar e inverter indicam melhor que o conceito tão diversamente utilizado de secularização aquilo que importa com vistas ao campo religioso.

7. "Crítica salvadora" indica o procedimento herdante de Bloch em relação à religião e à cultura. Ela extrai partes-herdadas úteis do contexto social transmitido e as insere em um novo, conforme o modelo da "arte-montagem".

Como a intervenção crítica de Bloch em debates sociais religiosamente carregados deve ser entendida é algo que pode ser visto de modo especial na obra Herança dessa época. O livro, surgido em 1934 em Zurique, analisa, com base no exemplo da República de Weimar, a decadência da sociedade burguesa nos anos vinte, extraindo daí como se tornou possível que, em meio à simultaneidade capitalista, se chegasse a uma “explosão da não-simultaneidade" (Bloch, 1977b, p. 203), a qual desembocou no fascismo (cf. Dietschy, 2018, p. 31-44). Mostra como a cultura de massas da "dispersão" [Zerstreuung] na crise passou para uma "intoxicação" [Berauschung] irracional. Bloch afirma que ninguém acreditou no "vazio da dispersão" no kitsch e no cinema, mas que, no "pathos nacional a partir do sangue" (Bloch, 1977b, p. 96), os nazistas acreditavam totalmente (cf. Bloch, 1977b, p. 59), o que para Bloch corresponde ao encobrimento e irrupção irracional de um estamento médio, tornado selvagem. Também os leitmotiv filosófico-populares de "vida" e "totalidade" e até a ideia, que uma vez foi utopicamente carregada, de um reino, passam por uma crítica apurada em Bloch. Simultaneamente, entretanto, são levados a sério como objeções antimecanicistas contra a racionalidade econômica, o desencantamento e a coisificação do mundo na empresa capitalista. Em contraposição a isso, Bloch quer introduzir um marxismo concreto-utópico (cf. Bloch, 1977b, 151), a fim de evitar que, por causa do economicismo marxista vulgar, "também o comunismo seja apresentado enquanto algo mecânico" (Bloch, 1977b, p. 67) ${ }^{20}$.

20 A redução do marxismo a um certo economicismo teria sido, inclusive, explorado com êxito pelos nazistas. Um episódio, que Bloch contou várias vezes, deixa isso claro: um pouco antes de 1933 ele estava em um grande evento político no Palácio dos Esportes de Berlim, onde um orador comunista e um nazista se confrontaram. Após o comunista ter falado por horas sobre a contradição fundamental entre o capital e a taxa média de lucros no Capital de Marx, o nazista agradeceu e dirigiu-se à plateia, na qual se encontravam numerosos membros da camada recém-formada de pequenos funcionários, com as seguintes palavras: "O que foi que vocês ouviram? Números, números e novamente números. O que vocês fazem o dia inteiro, quando estão sentados em seu escritório como pequeno contador? Escrever números. Aí se mostra que o comunismo e o capitalismo são apenas dois lados da mesma moeda". E

\begin{tabular}{|l|l|l|l|l|}
\hline Govista Dialectus & Ano 10 & n. 21 & Janeiro - Abril 2021 & p. 37-52 \\
\hline
\end{tabular}


O procedimento de Bloch, portanto, em relação ao não simultâneo e, em partes, ao anticapitalismo irracional-romântico, não é uma rejeição abstrata. Pode, antes, ser designada de "crítica salvadora" que une "esclarecimento e sabedoria dialética" (Bloch, 1977b, p. 155). Em Bloch, com isso, também se trata de uma reconquista daquelas esperanças uma vez consideradas revolucionárias, como é o caso das figuras milenares do "Terceiro Reino" [Dritten Reich], ocupadas pelos nacional-socialistas. "Se tem entregue à reação, sem resistência alguma, tanto o inferno quanto o céu, os berserkos quanto à teologia” (Bloch, 1977b, p. 66). Reconquistar esse reino e a sua força simbólica, no entanto, não é algo fácil. Só pode dar certo com uma práxis transformadora: "para poder ser herdado, o campo irracional precisa primeiro ser transformado" (Bloch, 1972, p. 205). Por isso não pode se tratar simplesmente de copiar ou (re) ocupar ${ }^{21}$ motivos não simultâneos ou mesmo fascistas, mas unicamente de um uso mediado, o qual os utiliza de modo diferenciado. Modelos para esse trabalho de transformação são os procedimentos surrealistas da colportagem e montagem.

A arte da transformação e da reconstrução, na medida em que compreende o seu tempo enquanto tempo de transição, lança, simultaneamente, um olhar de volta para o velho decadente a fim de descobrir aí heranças de algo útil. Para tanto, ela não precisa, conforme conclui Bloch em um olhar retrospectivo sobre seu livro, "apenas de esclarecimento em primeiro grau", portanto, olhares críticos e capacidade de expor e escolher, mas também, em segundo grau, de "uma fantasia tão exata quanto concreta" (Bloch, 1972, p. 60). E esta tem de certificar-se "de que a dialética, em meio à marcha e durante os atos do seu desencantamento, não se esqueça de ocupar as remanescentes e reais casas de tesouro" (Bloch, 1977b, p. 329). Isso tem muito pouca relação com ocupações táticas de símbolos da tradição e, muito menos ainda, com o cuidado de artefatos culturais. A herança de tesouros ainda não desvelados deve ser compreendida enquanto legado e tarefa que, mesmo que ancorada na história até a atualidade, ainda não foi realizada, podendo, contudo, ser validada e levada adiante.

O ponto de partida para essa herança salvadora é um interesse atualizado e prático-emancipatório, pois é na continuação do não simultâneo e do não realizado que se juntam todas as “contradições e intenções não cumpridas” (Bloch, 1977b, p. 117). Com

prossegue: "Eu falo para vocês em nome de algo mais elevado!”. A dizer: em nome de Hitler. (Nota elaborada pelo autor especificamente para a presente versão brasileira do texto. N.T.).

21 As sugestões táticas de Bloch (1977b), dadas em Erbschaft dieser Zeit (Herança dessa época), às vezes tendem a isso. Para saber mais, compare Dietschy, 2012.

\begin{tabular}{|l|l|l|l|l|}
\hline Q Povista Dialectus & Ano 10 & n. 21 & Janeiro - Abril 2021 & p. 37-52 \\
\hline
\end{tabular}


isso está indicado um importante critério para a identificação de heranças utilizáveis: elas hão de ser "perturbadoras na economia capitalista" (1977b, p. 218). Devem, por isso, enquanto contradições não simultâneas, poder impulsionar "a contradição surgida no colo da sociedade capitalista a partir do autêntico hoje, do hoje e do amanhã concreto" (1977b, p. 226).

\section{A transformação blochiana da religião a modifica em um transcender sem transcendência. A "explosão do princípio de poder e de classe" é o seu impulso.}

Não equivaleria, assim poderíamos nos perguntar, o superar do hoje rumo ao amanhã, “o transcendere - para adiante” (Bloch, 1977, p. 315) à nossa procura por transcendência? Isso Bloch negaria. Ele insiste em um transcender sem transcendência, pois leva a sério o caráter ambivalente do todo interesse herdado do transcender religioso. Para ele, existe aí "embriaguês em dupla forma: uma consolando a miséria, mas outra insurgente, que se contrapõe à mesma" (1977b, p. 133). Assim, as religiões, por meio das crenças no além e da fuga para a interioridade, contribuem para manter a miséria - "e o cristianismo contribuiu muito com ambas" (1977b, p. 133). Algo diferente, no entanto, consta nas manifestações quiliástico-messiânicas, pois, "quando o além quer se deslocar para a terra e a interioridade para a exterioridade, então surge, em vez de ópio, um meio explosivo sem igual no interior do fator subjetivo, uma vontade rumo ao céu sobre a terra" (1977b, p. 133).

É justamente essa vontade rumo a um reino do céu sobre a terra que, aos olhos de alguns críticos de Bloch, equivale a um delírio perigoso, o qual, do mesmo modo que o nacional-socialismo, buscaria estabelecer, pela violência, um reino milenar. Nisso, no entanto, é ocultada a centralidade do ponto metarreligioso do modo de exposição blochiano, o qual justamente quer desprender a crítica da dominação, constitutiva de uma tradição bíblico-profética, da sua projeção no além, a fim de conduzi-la a uma práxis emancipatória que busque a superação de todas as relações de dominação e servidão. Por esse motivo, Bloch percebe no fator subjetivo "algo explosivo" contra tendências de coisificação e perpetuação de relações de poder, especialmente quando essas se apresentam com a aura de uma ordem sacrossanta do mundo.

Não por acaso, a crítica metarreligiosa da religião encontrou, no "êxodo para fora da casa de escravidão do Egito", a sua linguagem simbólica central. Sua crítica não 
se volta apenas para o "outro lado", mas, da mesma forma, para o "lá em cima", nomeadamente o mais alto e que, afinal de contas, legitima todas as dominações. Essa crítica conduz para a "saída da concepção cesarista de Deus" (Bloch, 1977, p. 165), levando para uma reformulação da transcendência rumo a uma imanência transcendente (cf. Bloch, 2006, p. 372). Portanto, o ateísmo de Bloch transforma aquilo que se compreendia como Deus, sem, no entanto, de modo algum, derivar da imanência “celestial” algum tipo de "entidade entronizada' (2006, p. 377), mas, antes, algo apenas indicado metaforicamente enquanto "reino" humano-escatológico. Com isso, Bloch não hipostasia uma situação futura, nem uma "terra do futuro" (Cf. Folkers, 1997, p. 126), mas compreende esse espaço enquanto espaço do transcender "para o interior da imanência que ainda não se tornou" (Bloch, 1985, p. 413) e ainda requer mais superações, mesmo que essas signifiquem, conforme seu conteúdo de esperança, um "transcender completamente sem autoestranhamento [ohne Selbstentfremdung]" (Bloch, 1977, p. 317).

Transcender é um processo inacabado de superação de realizações inadequadas do humano. Medida e impulso para a superação é a explosão "do próprio princípio das classes e de poder" (Bloch, 1973, p. 106) rumo à sua transformação por meio de uma práxis social autorrealizadora e não estranhada. No livro sobre T. Münzer, Bloch nomina isso de - fazendo uso da linguagem bíblica simultaneamente transformada - “o princípio metapolítico, metarreligioso de toda revolução: a irrupção de liberdade dos filhos de Deus" (Bloch, 1973, p. 202). Não é algo repentino. Práxis emancipatórias dependem, especialmente no campo religioso, de processos de transformação profundos e amplos. Metarreligião, portanto, não significa apenas religião herdada, mas também uma religião transformada e liberta de estranhamento e dominação, a qual contribui para a formação de ornamentos da "humanidade inconclusa [unausgeschöpften] e utópica" (1977b, p. 263).

\section{Referências}

BLOCH, Ernst. Atheismus im Christentum. Zur Religion des Exodus und des Reichs. Gesamtausgabe 14. Frankfurt a. M.: Suhrkamp, 1977.

BLOCH, Ernst. Die rätselhafte Unzufriedenheit. In: BLOCH, Ernst. Durch die Wüste. Kritische Essays. Berlin: Paul Cassirer Verlag, 1923.

BLOCH, Ernst. Die Rückkehr ins Jetzt. In: BLOCH, Ernst. Durch die Wüste. Kritische Essays. Berlin: Paul Cassirer Verlag, 1923a. 
BLOCH, Ernst. Experimentum mundi. Fragen, Kategorien des Herausbringens, Praxis. Gesamtausgabe 15. Frankfurt a. M.: Suhrkamp, 1977a.

BLOCH, Ernst. Erbschaft dieser Zeit. Gesamtausgabe 04. Frankfurt a. M.: Suhrkamp,1977b.

BLOCH, Ernst. Geist der Utopie. Erste Fassung. Gesamtausgabe 16. Frankfurt a. M.: Suhrkamp, 1977c.

BLOCH, Ernst. Geist der Utopie. Zweite Fassung. Gesamtausgabe 03. Frankfurt a. M.: Suhrkamp, 1977d.

BLOCH, Ernst. O Princípio Esperança, v. I. Tradução de Nélio Schneider. Rio de Janeiro: EdUERJ: Contraponto, 2005.

BLOCH, Ernst. O Princípio Esperança, v. III. Tradução de Nélio Schneider. Rio de Janeiro: EdUERJ: Contraponto, 2006.

BLOCH, Ernst. Processus et structure. In: GADILLAC, Maurice; GOLDMANN, Lucien; PIAGET, Jean (Org.). Entretiens sur les notions de Genèse et de structure, Actes du Colloque de Cerisy. Paris/La Haye: Hermann, 1959.

BLOCH, Ernst. Literarische Aufsätze. Gesamtausgabe 09. Frankfurt a. M., Suhrkamp,1977e.

BLOCH, Ernst. Spuren. Gesamtausgabe 01. Frankfurt a. M.: Suhrkamp, 1977f.

BLOCH, Ernst. Thomas Münzer als Theologe der Revolution. Gesamtausgabe 02. Frankfurt a. M.: Suhrkamp, 1921/1977g.

BLOCH, Ernst. Thomas Münzer, teólogo da revolução. Rio de Janeiro: Biblioteca Tempo Universitário, 1973.

BLOCH, Ernst. Tanz- und Schlachthaus. In: BLOCH, Ernst. Fabelnd denken. Essayistische Prosa aus der "Frankfurter Zeitung". Tübingen: Verlag Klöpfer \& Meyer, 1997.

BLOCH, Ernst. Tendenz - Latenz - Utopie. Ergänzungsband zur Gesamtausgabe. Suhrkamp: Frankfurt a. M. , 1985.

BLOCH, Ernst. Vom Hasard zur Katastrophe. Politische Aufsätze aus den Jahren 1934-1939, Suhrkamp: Franfkfurt a. M. , 1972.

BLUMENBERG, Hans. Die Legitimität der Neutzeit. Frankfurt a. M.: Suhrkamp, 1966. BLUMENTRITT, Marin. Etwas Fehlt - Die Möglichkeit denken. In: ZEILINGER, Doris (Org.). VorSchein 35. Jahrbuch 2017 der Ernst-Bloch-Assoziation. Der Zukunft auf der Spur. Nürnberg; Antogo Verlag, 2018, p. 67-76. 
BRECHT, Bertold. Ascensão e queda da cidade de Mahagonny. In: BRECHT, Bertold. Teatro completo. Tradução de Luiz Antônio Martinez Corrêa e Wolfgang Bader. V. 03. Rio de Janeiro: Paz e Terra, 1995.

BRECHT, Bertold; WEILL, Kurt. A ópera dos três vinténs. Tradução de Wolfgang Bader e Marcos Roma Santa. In: BRECHT, Bertold. Teatro completo. V. 03. Rio de Janeiro: Paz e Terra, 1995.

BROWN, Wendy. Wie säkular ist Marx`Kapital? In: JAEGGI, Rafael; LOICK, Daniel (Org.). Nach Marx: Philosophie, Kritik, Praxis. Berlin: Suhrkamp, 2013.

BÖCKENFÖRDE, Ernst-Wolfgang. Die Entehung des Staates als Vorgang der Säkularisation. In: SCHREY, Heinz-Horst. Säkularisierung. Darmstadt: Wissenschaftliche Buchgesellschaft, 1981.

DERRIDA, Jacques. Marx'Gespenster. Frankfurt a. M. 2004.

DIETSCHY, Beat. Transzendieren der Transzendenz. Ernst Blochs Versuch, Religion neu zu denken. In: ZIMMERMANN, Rainer (Org.): Ontologische Probleme der Grundlegung nach Schelling und Bloch. Hamburg: Verlag Dr. Kovac, 2018, p. 11-28.

DIETSCHY, Beat. Im Mischdunkel natinaler Barauchung. Ernst Bloch Erbschaft dieser Zeit. In: Zeiten des Rechtspopulismus gelesen. Hamburg: Argument Heft 235: 2018, p. $31-44$.

DIETSCHY, Beat. Ungleichzeitigkeit, Gleichzeitigkeit, Übergleichzeitigkeit. In: DIETSCHY, Beat; ZEILINGER, Doris; ZIMMERMANN, E. Rainer (Org.): BlochWörterbuch. Leitbegriffe der Philosophie Ernst Bloch. Berlin/Boston: De Gruyter, 2012.

FOLKERS, Horst. Transzendenz und Utopie in Blochs Atheismus im Christentum. In: GOODMAN-THAU, Eveline (Org.). Vom Jenseits. Jüdisches Denken in der europäischen Geistesgeschichte. Berlin: Akademie Verlag, 1997.

HORN, Johannes. Vorwort. In: HORN, Johannes (Org.). Ernst Bloch Revision des Marxismus. Kritische Auseinandersetzung marxistischer Wissenschaftler mit der Blochsche Philosophie. Berlin: Deutscher Verlag der Wissenschaften, 1957.

HORN, Johannes. Kritische Bemerkungen zur Philosophie Ernst Bloch. In: HORN, Johannes (Org.). Ernst Bloch Revision des Marxismus. Kritische Auseinandersetzung marxistischer Wissenschaftler mit der Blochsche Philosophie. Berlin: Deutscher Verlag der Wissenschaften, 1957a.

LÖWITH, Karl. Weltgeschichte und Heilgeschichte. Die Theologischen Voraussetzungen der Geschichtsphilosophie. Zürch/Wien: Kohlhammer, 1953.

MARX, Karl. O Capital, v. I. São Paulo: Abril Cultural, 1983.

MARX, Karl. Anmerkungen zur Doktordissertation. In: $M E W$. Ergänzungsband I, Berlin: Dietz Verlag, 1973. 
PONGRATZ, Ludwig J. Philosophie in Selbsdarstellung. Hamburg: Meiner, 1975.

ROULET, Gerard. Die Utopie des Reiches. In: ZIMMERMANN, Rainer (Org.). Ernst Bloch: Das Prinzip Hoffnung. Berlin/Boston: De Gruyter, 2017. Doi: 10.1515/9783110366136-021.

SÖLLE, Dorothee. Die Übernahme des Säkularisierungsbegriffs in die Lieteraturwissenschaft. In: SCHREY, Heinz-Horst. Säkularisierung. Darmstadt: Wissenschaftliche Buchgesellschaft, 1981.

VIDAL, Francesca; MÜLLER-SCHÖLL, Ulrich. Sein wie Hoffnung. Näherungen an Gelungenheit. In: ZIMMERMANN, Rainer (Org.). Ernst Bloch: Das Prinzip Hoffnung. Berlin/Boston: De Gruyter, 2017. Doi: 10.1515/9783110366136-005. 